\title{
THE EFFICIENCY OF THE GAVER-STEHFEST METHOD TO SOLVE ONE-DIMENSIONAL GAS FLOW MODEL
}

\author{
Małgorzata Wójcik', Mirosław Szukiewicz', Paweł Kowalik², Wiesław Próchniak² \\ 1 Department of Chemical and Process Engineering,The Faculty of Chemistry, Rzeszow University of Technology, \\ al. Powstańców Warszawy 12, 35-959 Rzeszow, Poland, e-mail: wojcik.mm@op.pl, ichms@prz.edu.pl \\ 2 Institute of New Chemical Synthesis, al. Tysiąclecia Państwa Polskiego 13a, 24-110 Pulawy, Poland, e-mail: \\ pawel.kowalik@ins.pulawy.pl,wiesław.prochniak@ins.pulawy.pl
}

Received: 2016.12.15

Accepted: 2017.02.01

Published: 2017.03.01

\begin{abstract}
In this paper we examined the efficiency of one of the methods for numerical inversion of the Laplace transform: the Gaver-Stehfest method to find a solution to a onedimensional gas flow model with axial dispersion. The algorithm was used to determine values of the axial dispersion coefficients $D_{L}$ and Pèclet numbers Pe on the basis of the pulse tracer technique. The obtained results of Pèclet numbers indicate that the gas flow is neither plug flow nor perfect mixing under operation condition. Numerical results are provided to confirm the efficiency of the presented method. Calculations were performed with the use of the CAS program type (Maple $\left.{ }^{\circledR}\right)$.
\end{abstract}

Keywords: Laplace transform, method for numerical inversion of the Laplace transform, axial dispersion coefficient, program Maple ${ }^{\circledR}$.

\section{INTRODUCTION}

Methods for numerical inversion of the Laplace transform have enjoyed popularity in the field of science and engineering since at least the 1930s. The methods are a very helpful 'tool of mathematics' to solve problems of mathematics, physics, chemistry and engineering which are described inter alia by a system of differential equations. In many cases, an analytical inversion of problems to the time domain can be difficult or even impossible to obtain. Many scientists used numerical algorithms of inverse Laplace transform to find a solution in the time domain of transport problems. For example, Chen [2] and Zhan et al. $[13,14]$ have successfully employed the Stehfest algorithm to obtain a solution in the time domain for the solute transport problems. Chen et al. [3] used the Crump method to obtain a solution of the radial dispersion in the realtime domain from the Laplace domain. Kocabas [8] presented two algorithms of inverse Laplace transform, the Stehfest method and the Dubner and Abate method to modeling of tracer transport in heterogeneous porous media and estimating parameters of systems (e.g Pèclet number). Wang and Zhan [11] recommended the Stehfest method, the Honig and Hirdes method, and the Zakian method for dispersion problems. According to literature reports, the method based on combination of Gaver functionals (the Gaver-Stehfest method) have been applied successfully to find solution in the time domain of transport problems [7, 9].

In this paper, the efficiency of method for numerical inversion of the Laplace transform based on combination of Gaver functionals - the Gaver-Stehfest method for solving an axial dispersion model is presented. Axial dispersion coefficients $\mathrm{D}_{\mathrm{L}}$ and Pèclet numbers Pe for measuring system are estimated.

\section{The Gaver-Stehfest method}

The Gaver-Stehfest method is a simple algorithm for the numerical inversion of the Laplace transform which has been used successfully by several authors for many problems $[4,10,5]$. 
This method approximates the time domain solution as [15]

$$
\mathrm{f}(\mathrm{t})=\frac{\ln 2}{\mathrm{t}} \sum_{\mathrm{k}=1}^{\mathrm{N}} \mathrm{V}_{\mathrm{k}} \cdot \mathrm{F}\left(\mathrm{k} \cdot \frac{\ln 2}{\mathrm{t}}\right)
$$

where $V_{k}$ is described by the following equation

$$
\mathrm{V}_{\mathrm{k}}=(-1)^{\mathrm{k}+\frac{\mathrm{N}}{2}} \sum_{j=\left(\frac{\mathrm{k}+1}{2}\right)}^{\min \left(k, \frac{N}{2}\right)} \frac{\mathrm{j}^{\frac{N}{2}}(2 \mathrm{j}) !}{\left(\frac{\mathrm{N}}{2}-\mathrm{j}\right) ! \mathrm{j} !(j-1) !(k-j) !(2 j-k) !}
$$

The parameter $\mathrm{N}$ is called the Stehfest number N. It is the number of terms used in Eq. (1). Parameter $\mathrm{N}$ must be an even integer, it should be chosen by trial and error method. The precision of calculation depends on the parameter $\mathrm{N}$ because the inversion is based on a summation of $\mathrm{N}$ weighted values. Theoretically, the large value of parameter $\mathrm{N}$ determines a more accurate solution but if $\mathrm{N}$ is too large, the results may be worsened due to round-off errors. Thus, a suitable choice of value $\mathrm{N}$ is important to achieve the most accurate solution [6]. Many authors propose a different value of the parameter $\mathrm{N}$ to obtain the most accurate solution. For example, Cheng and Sidauruk recommended that optimal choice of $\mathrm{N}$ should be in a range from 6 to 20 [1].

\section{DESCRIPTION OF THE EXPERIMENTS}

The main objective of this work is to find a simple and effective method to find values of coefficients $\left(\mathrm{D}_{\mathrm{L}}\right.$ or Pe) of axial gas dispersion model. The scheme of the measuring system can be seen in Figure 1.

Zone 1: the pipe connected the 6-way valve outlet and the 6-way valve inlet; the length of the zone: $2.0000 \cdot 10^{-2}[\mathrm{~m}]$, the diameter of the zone: $1.5875 \cdot 10^{-3}[\mathrm{~m}]$.

Zone 2: empty reactor; the length of the zone: $1.7700 \cdot 10^{-1}[\mathrm{~m}]$, the diameter of the zone: $7.6500 \cdot 10^{-3}[\mathrm{~m}]$.

Zone 3: the pipe connected a reactor outlet and the 6-way valve; the length of the zone: $2.3500 \cdot 10^{-1}[\mathrm{~m}]$, the diameter of the zone: $1.5875 \cdot 10^{-3}[\mathrm{~m}]$.



Fig. 1. The schematic representation of the measuring system: 1 - reactor, 2 - the 6 -way valve, 3 - sample loop, 4 - pipe 
Zone 4: the pipe connected the 6-way valve and TCD detector; the length of the zone: $5.5000 \cdot 10^{-1}$ $[\mathrm{m}]$, the diameter of the zone: $1.5875 \cdot 10^{-3}[\mathrm{~m}]$

The study was conducted as follows. The system was flushed for 15-30 minutes with a constant flow of heliumuntil a stable TCD signal was received. At the same time, the volume of sample loop $\left(2.5000 \cdot 10^{-7} ; 5.0000 \cdot 10^{-7}\left[\mathrm{~m}^{3}\right]\right)$ was flushed also with a constant flow of nitrogen. Next, the 6 -way valves were opened to allow the flow of helium with the constant volumetric flow rate (of $3.3333 \cdot 10^{-7}$ or $5.0000 \cdot 10^{-7}$ or $6.6667 \cdot 10^{-7}\left[\mathrm{~m}^{3} / \mathrm{s}\right]$ ) through the sample loop, all zones to detector TCD. TCD signal was recorded. All experiments were conducted at pressure $1.0000 \cdot 10^{5}[\mathrm{~Pa}]$ and temperature $313[\mathrm{~K}]$.

\section{ASSUMPTIONS OF THE MODEL}

The presented model is based on the following assumptions:

- the system is operated under isothermal conditions and constant pressure,

- gases satisfy the equation of the state of an ideal gas.

\section{MASS BALANCE OF THE PROCESS}

Mass balance of the nitrogen in each zones can be described by the following a system of partial differential equations and the initial and boundary conditions:

Zone 1:

$$
\begin{gathered}
\frac{\partial c(x, t)}{\partial t}=D_{L, 1} \frac{\partial^{2} c(x, t)}{\partial x^{2}}-\frac{4 F_{v}}{\pi d_{w, 1}^{2}} \cdot \frac{\partial c(x, t)}{\partial x} \\
\text { IC: } c(x, 0)=0 \\
\text { BC: } \frac{4 F_{v}}{\pi d_{w, 1}^{2}} \cdot c_{0}=\frac{4 F_{v}}{\pi d_{w, 1}^{2}} \cdot c\left(0^{+}, t\right)-\left.D_{L, 1} \frac{\partial c(x, t)}{\partial x}\right|_{x=0^{+}} \\
\left.\frac{\partial c(x, t)}{\partial x}\right|_{x=L_{1}^{+}}=\left.\frac{\partial c(x, t)}{\partial x}\right|_{x=L_{1}^{-}}
\end{gathered}
$$

Zone 2:

$$
\begin{gathered}
\frac{\partial \mathrm{c}(\mathrm{x}, \mathrm{t})}{\partial \mathrm{t}}=\mathrm{D}_{\mathrm{L}, 2} \frac{\partial^{2} \mathrm{c}(\mathrm{x}, \mathrm{t})}{\partial \mathrm{x}^{2}}-\frac{4 \mathrm{~F}_{\mathrm{v}}}{\pi \mathrm{d}_{\mathrm{w}, 2}^{2}} \cdot \frac{\partial \mathrm{c}(\mathrm{x}, \mathrm{t})}{\partial \mathrm{x}} \\
\operatorname{IC:} \mathrm{c}(\mathrm{x}, 0)=0 \\
\text { BC: } \mathrm{c}\left(\mathrm{L}_{1}^{+}, \mathrm{t}\right)=\mathrm{c}\left(\mathrm{L}_{1}^{-}, \mathrm{t}\right) \\
\left.\frac{\partial \mathrm{c}(\mathrm{x}, \mathrm{t})}{\partial \mathrm{x}}\right|_{\mathrm{x}=\left(\mathrm{L}_{1}+\mathrm{L}_{2}\right)^{+}}=0
\end{gathered}
$$

Zone 3:

$$
\begin{gathered}
\frac{\partial c(x, t)}{\partial t}=D_{L, 3} \frac{\partial^{2} c(x, t)}{\partial x^{2}}-\frac{4 F_{v}}{\pi d_{w, 3}^{2}} \cdot \frac{\partial c(x, t)}{\partial x} \\
\text { IC: } c(x, 0)=0 \\
\text { BC: } c\left(L_{1}+L_{2}^{+}, t\right)=c\left(L_{1}+L_{2}^{-}, t\right) \\
\left.\frac{\partial c(x, t)}{\partial x}\right|_{x=\left(L_{1}+L_{2}+L_{3}\right)^{+}}=0
\end{gathered}
$$


Zone 4:

$$
\begin{gathered}
\frac{\partial c(x, t)}{\partial t}=D_{L, 4} \frac{\partial^{2} c(x, t)}{\partial x^{2}}-\frac{4 F_{v}}{\pi d_{w, 4}^{2}} \cdot \frac{\partial c(x, t)}{\partial x} \\
\text { IC: } c(x, 0)=0 \\
\text { BC: } c\left(L_{1}+L_{2}+L_{3}^{+}, t\right)=c\left(L_{1}+L_{2}+L_{3}^{-}, t\right) \\
\frac{\partial c(x, t)}{\partial x} I_{x=\left(L_{1}+L_{2}+L_{3}+L_{4}\right)^{+}}=0
\end{gathered}
$$

$\mathrm{c}\left(\mathrm{L}_{1}+\mathrm{L}_{2}+\mathrm{L}_{3}+\mathrm{L}_{4}, \mathrm{t}\right)$ corresponds concentration recorded by TCD-detector. We assumed that $\mathrm{D}_{\mathrm{L}, 1}=\mathrm{D}_{\mathrm{L}, 3}=$ $\mathrm{D}_{\mathrm{L}, 4}$ due tu the same diameter of pipes. Inlet concentration can be described by rectangular pulse:

$$
c_{0}=\left\{\begin{array}{c}
0 \text { for } t<0 \\
c_{T} \text { for } 0 \leq t \leq \frac{V_{i m p}}{F_{v}} \\
0 \text { for } t>\frac{V_{i m p}}{F_{v}}
\end{array}\right.
$$

where: $\mathrm{C}_{\mathrm{T}}=\mathrm{P} / \mathrm{R}_{\mathrm{g}} \cdot \mathrm{T} \cdot 10^{3}=3.906 \cdot 10^{-2}\left[\mathrm{kmol} / \mathrm{m}^{3}\right]$,

$\mathrm{F}_{\mathrm{v}}-$ the volumetric flow rate $\left[\mathrm{m}^{3} / \mathrm{s}\right]$.

\section{RESULTS}

To obtain the outlet concentration of tracer $\mathrm{c}\left(\mathrm{L}_{1}+\mathrm{L}_{2}+\mathrm{L}_{3}+\mathrm{L}_{4}, \mathrm{t}\right)$, we solved a system of partial differential equations Eq. (2-5) with appropriate initial and boundary conditions, by applying Laplace transform technique. The solution of model in Laplace domain may be written as

$$
\overline{\mathrm{c}}\left(\mathrm{L}_{1}+\mathrm{L}_{2}+\mathrm{L}_{3}+\mathrm{L}_{4}, \mathrm{~s}\right)=\frac{\mathrm{M}}{\mathrm{N}} \cdot \mathrm{c}_{0}
$$

where:

$$
\begin{aligned}
& M=-\left(64 F_{v} \cdot e^{(A+B)}\left(D_{L, 1} \cdot \pi^{2} \cdot d_{w, 1}^{4} \cdot s+2 F_{v}\left(2 F_{v}-a\right)\right) \cdot e^{(C+D)\left(L_{1}+L_{2}\right)} \cdot e^{(E+F)\left(L_{1}+L_{2}+L_{3}\right)} .\right. \\
& \left.\left.\cdot \mathrm{e}^{(\mathrm{G}+\mathrm{H})\left(\mathrm{L}_{1}+\mathrm{L}_{2}+\mathrm{L}_{3}+\mathrm{L}_{4}\right)} \cdot \mathrm{b} \cdot \mathrm{c} \cdot \mathrm{d}\right)\right) \\
& \mathrm{N}=\left(2 \mathrm{~F}_{\mathrm{v}}-\mathrm{a}\right)\left(\mathrm{D}_{\mathrm{L}, 1} \cdot \pi^{2} \cdot \mathrm{d}_{\mathrm{w}, 1}^{4} \cdot \mathrm{s} \cdot \mathrm{e}^{(\mathrm{A}-\mathrm{B}) \mathrm{L}_{1}}+8 \mathrm{~F}_{\mathrm{v}}^{2} \cdot \mathrm{e}^{(\mathrm{A}-\mathrm{B}) \mathrm{L}_{1}}-4 \mathrm{~F}_{\mathrm{v}} \cdot \mathrm{e}^{(\mathrm{A}-\mathrm{B}) \mathrm{L}_{1}} \cdot \mathrm{a}\right)\left(2 \mathrm{~F}_{\mathrm{v}} \cdot\right. \\
& \left.\cdot \mathrm{e}^{(\mathrm{C}-\mathrm{D})\left(\mathrm{L}_{1}+\mathrm{L}_{2}\right)} \cdot \mathrm{e}^{(\mathrm{D}-\mathrm{C}) \cdot \mathrm{L}_{1}}-\mathrm{e}^{(\mathrm{C}-\mathrm{D})\left(\mathrm{L}_{1}+\mathrm{L}_{2}\right)} \cdot \mathrm{e}^{(\mathrm{D}-\mathrm{C}) \mathrm{L}_{1}} \cdot \mathrm{b}\right)\left(2 \mathrm{~F}_{\mathrm{V}} \cdot \mathrm{e}^{(\mathrm{E}-\mathrm{F})\left(\mathrm{L}_{1}+\mathrm{L}_{2}+\mathrm{L}_{3}\right)} \cdot\right. \\
& \left.\cdot \mathrm{e}^{(\mathrm{F}-\mathrm{E})\left(\mathrm{L}_{1}+\mathrm{L}_{2}\right)}-\mathrm{e}^{(\mathrm{E}-\mathrm{F})\left(\mathrm{L}_{1}+\mathrm{L}_{2}+\mathrm{L}_{3}\right)} \cdot \mathrm{e}^{(\mathrm{F}-\mathrm{E})\left(\mathrm{L}_{1}+\mathrm{L}_{2}\right)} \cdot \mathrm{c}\right)\left(2 \mathrm{~F}_{\mathrm{v}} \cdot \mathrm{e}^{(\mathrm{G}-\mathrm{H})\left(\mathrm{L}_{1}+\mathrm{L}_{2}+\mathrm{L}_{3}+\mathrm{L}_{4}\right)} \cdot\right. \\
& \left.\cdot \mathrm{e}^{(\mathrm{H}-\mathrm{G})\left(\mathrm{L}_{1}+\mathrm{L}_{2}+\mathrm{L}_{3}\right)}-\mathrm{e}^{(\mathrm{G}-\mathrm{H})\left(\mathrm{L}_{1}+\mathrm{L}_{2}+\mathrm{L}_{3}+\mathrm{L}_{4}\right)} \cdot \mathrm{e}^{(\mathrm{H}-\mathrm{G})\left(\mathrm{L}_{1}+\mathrm{L}_{2}+\mathrm{L}_{3}\right)} \cdot \mathrm{d}\right)
\end{aligned}
$$

where:

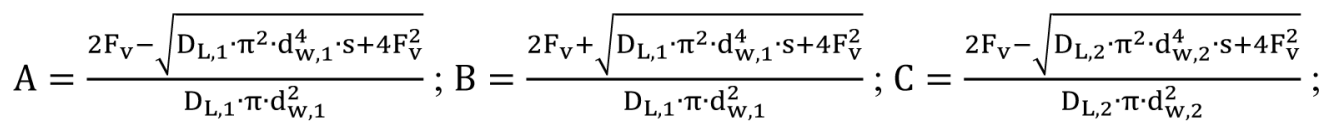

$$
\begin{aligned}
& \mathrm{D}=\frac{2 \mathrm{~F}_{\mathrm{v}}+\sqrt{\mathrm{D}_{\mathrm{L}, 2} \cdot \pi^{2} \cdot \mathrm{d}_{\mathrm{w}, 2}^{4} \cdot \mathrm{S}+4 \mathrm{~F}_{\mathrm{V}}^{2}}}{\mathrm{D}_{\mathrm{L}, 2} \cdot \pi \cdot \mathrm{d}_{\mathrm{w}, 2}^{2}} ; \mathrm{E}=\frac{2 \mathrm{~F}_{\mathrm{v}}-\sqrt{\mathrm{D}_{\mathrm{L}, 3} \cdot \pi^{2} \cdot \mathrm{d}_{\mathrm{w}, 3}^{4} \cdot \mathrm{S}+4 \mathrm{~F}_{\mathrm{V}}^{2}}}{\mathrm{D}_{\mathrm{L}, 3} \cdot \pi \cdot \mathrm{d}_{\mathrm{w}, 3}^{2}} ; \mathrm{F}=\frac{2 \mathrm{~F}_{\mathrm{v}}+\sqrt{\mathrm{D}_{\mathrm{L}, 3} \cdot \pi^{2} \cdot \mathrm{d}_{\mathrm{w}, 3}^{4} \cdot \mathrm{S}+4 \mathrm{~F}_{\mathrm{V}}^{2}}}{\mathrm{D}_{\mathrm{L}, 3} \cdot \pi \cdot \mathrm{d}_{\mathrm{w}, 3}^{2}} ;
\end{aligned}
$$

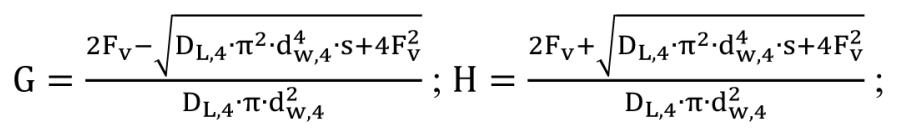




$$
\begin{aligned}
& a=\sqrt{D_{L, 1} \cdot \pi^{2} \cdot d_{w, 1}^{4} \cdot s+4 F_{v}^{2}} ; b=\sqrt{D_{L, 2} \cdot \pi^{2} \cdot d_{w, 2}^{4} \cdot s+4 F_{v}^{2}} ; c=\sqrt{D_{L, 3} \cdot \pi^{2} \cdot d_{w, 3}^{4} \cdot s+4 F_{v}^{2}} \\
& d=\sqrt{D_{L, 4} \cdot \pi^{2} \cdot d_{w, 4}^{4} \cdot s+4 F_{v}^{2}}
\end{aligned}
$$

$\mathrm{s}$ - the Laplace transform parameter.

Solution of Eq. (6) in the time domain was obtained using the Gaver-Stehfest method. The Gaver-Stehfest algorithm was chosen on the basis of previous tests. Accuracy of this algorithm was investigated for test functions and simplified model of a real gas flow. Details are presented in [12]. Parameter N called 'parameter of accuracy' for this method was determined by trial and error method. $\mathrm{N}=30$ was assumed as an optimal value for computations. All calculations were carried out with precision up to 48 decimal digits using Maple ${ }^{\circledR} 17$. Number of measurement points is equal to 70 .

The obtained results are presented in Figures 2 and 3. In all cases, very good fit between numerical and experiment curves is observed. The results showed that the GaverStehfest method can solve the gas flow problem with high accuracy (the minimal standard deviation is equal to $7.1765 \cdot 10^{-4}$, obtained for parameter $\mathrm{N}=30$ ) and fast (time of calculations $\mathrm{t}=58.4$ [s] for $\mathrm{N}=30$ ). Proper value parameter $\mathrm{N}$ was determined by trial and error method as in [12]. Finally, $N=30$ was an optimal value of parameter $\mathrm{N}$ for solution of axial gas dispersion model.

In this work, we used a pulse tracer technique to determine the axial dispersion coefficients of the gas phase and value of Pèclet numbers in the zones of system. The nitrogen was been used as a tracer. The inverse problem (see Eq. 6) was solved by combina-

File Edit View Insert Format Table Drawing Plot Spreadsheet Tools Window Help

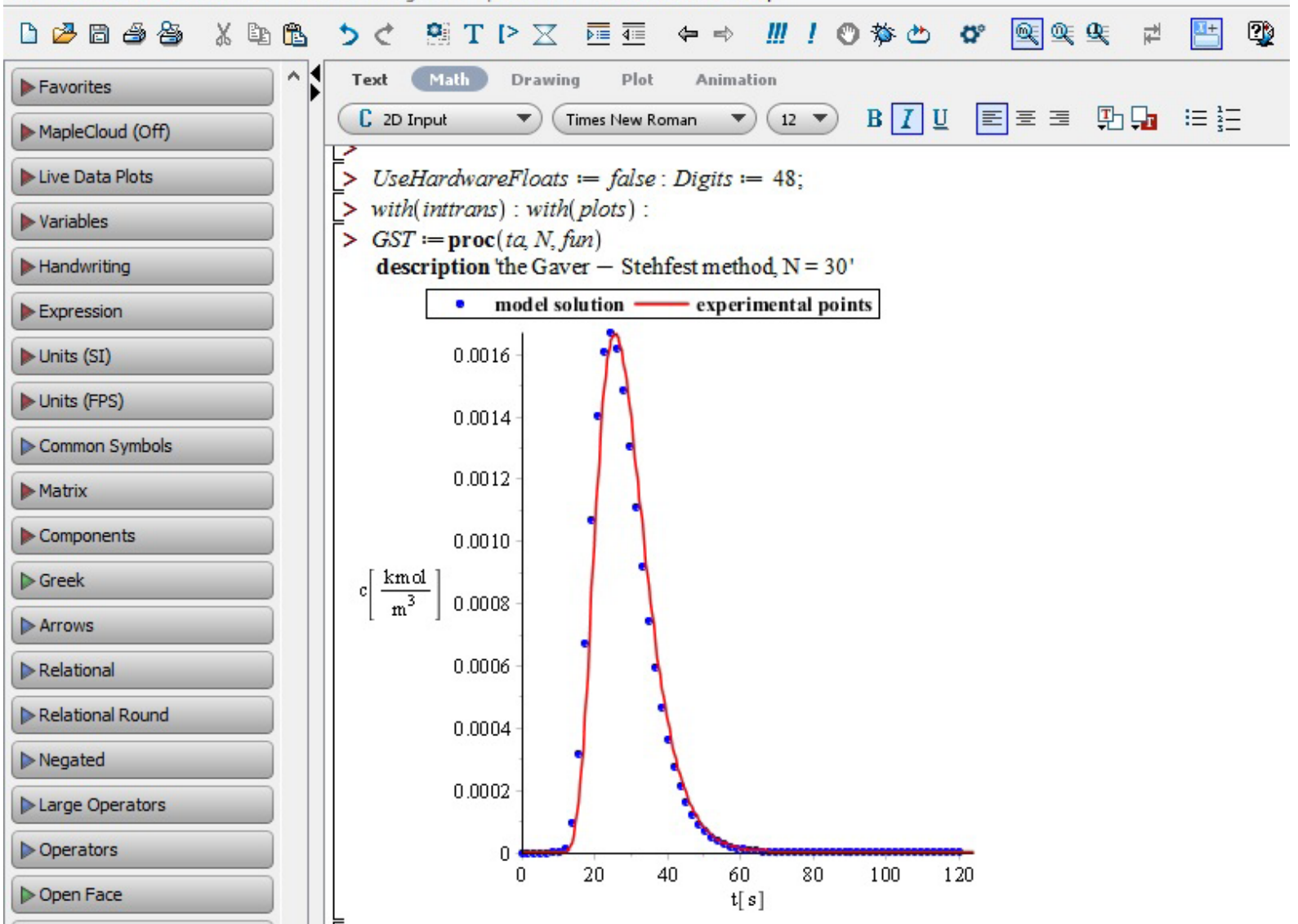

Fig. 2. Numerical (solid red line) and experimental (blue points) profiles of gas concentration for the volumetric flow rate $3.3333 \cdot 10^{-7}\left[\mathrm{~m}^{3} / \mathrm{s}\right]$ and the volume of sample loop $2.5000 \cdot 10^{-7}\left[\mathrm{~m}^{3}\right]$. Screenshot of program Maple ${ }^{\circledR}$ 
File Edit View Insert Format Table Drawing Plot Spreadsheet Tools Window Help

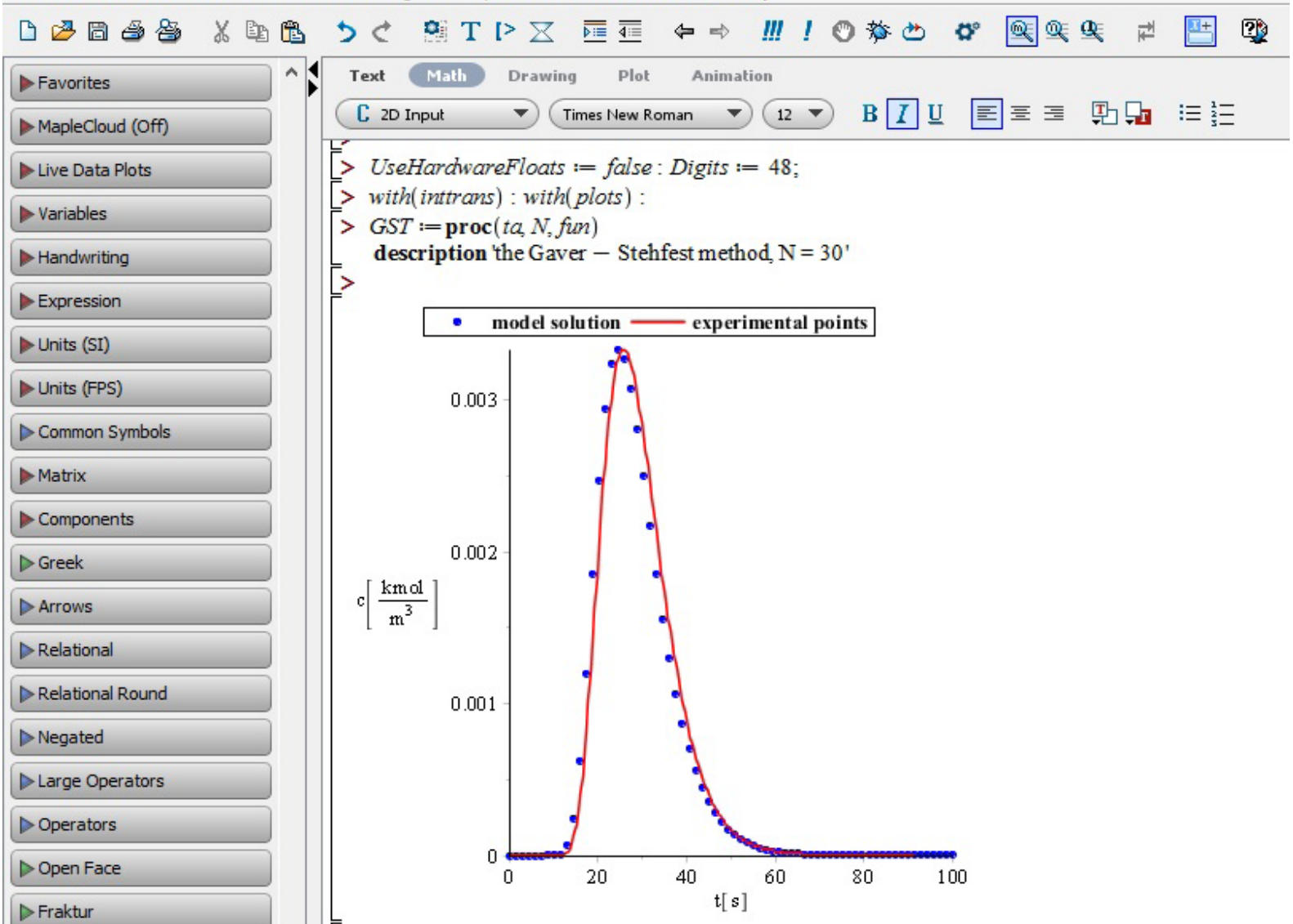

Fig. 3. Numerical (solid red line) and experimental (blue points) gas concentration profiles for the volumetric flow rate $3.3333 \cdot 10^{-7}\left[\mathrm{~m}^{3} / \mathrm{s}\right]$ and the volume of sample loop 5.0000 $10^{-7}\left[\mathrm{~m}^{3}\right]$. Screenshot of program Maple ${ }^{\circledR}$

Table 1. Values of axial dispersion coefficients and Pèclet numbers

\begin{tabular}{|c|c|c|c|c|}
\hline $\begin{array}{l}\text { Volume of impulse of gas } \\
\qquad V_{\text {imp }}\left[\mathrm{m}^{3}\right]\end{array}$ & $\begin{array}{c}\text { Volumetric flow rate } \\
\mathrm{F}_{\mathrm{v}}\left[\mathrm{m}^{3} / \mathrm{s}\right]\end{array}$ & $\begin{array}{c}\text { Number of } \\
\text { zone }\end{array}$ & $\begin{array}{l}\text { Axial dispersion coefficient } \\
\qquad D_{L}\left[\mathrm{~m}^{2} / \mathrm{s}\right]\end{array}$ & $\begin{array}{c}\text { Pèclet number } \\
\mathrm{Pe}\end{array}$ \\
\hline \multirow{12}{*}{$2.5000 \cdot 10^{-7}$} & \multirow{4}{*}{$3.3333 \cdot 10^{-7}$} & 1 & $7.7700 \cdot 10^{-4}$ & 4.3 \\
\hline & & 2 & $7.8000 \cdot 10^{-5}$ & 16.5 \\
\hline & & 3 & $7.7700 \cdot 10^{-4}$ & 51.0 \\
\hline & & 4 & $7.7700 \cdot 10^{-4}$ & 119.3 \\
\hline & \multirow{4}{*}{$5.0000 \cdot 10^{-7}$} & 1 & $1.7826 \cdot 10^{-3}$ & 28.4 \\
\hline & & 2 & $7.9000 \cdot 10^{-5}$ & 24.4 \\
\hline & & 3 & $1.7826 \cdot 10^{-3}$ & 33.3 \\
\hline & & 4 & $1.7826 \cdot 10^{-3}$ & 78.0 \\
\hline & \multirow{4}{*}{$6.6667 \cdot 10^{-7}$} & 1 & $3.1284 \cdot 10^{-3}$ & 21.5 \\
\hline & & 2 & $8.0000 \cdot 10^{-5}$ & 32.1 \\
\hline & & 3 & $3.1284 \cdot 10^{-3}$ & 25.3 \\
\hline & & 4 & $3.1284 \cdot 10^{-3}$ & 59.2 \\
\hline
\end{tabular}

tion of 'trial -and-error' procedure and inner optimization procedure of the program Maple. As the correct value of parameter $\mathrm{D}_{\mathrm{L}}$ was accepted this, for which the standard deviation between numerical and experimental results was the lowest. The results are presented in Tables 1 and 2.

\section{CONCLUSIONS}

The main results of the paper can be summarized as follows:

1. Application of the Gaver-Stehfest method is suitable for a solution of one-dimensional gas flow model. It works fast and with high accuracy. 
Table 2. Values of axial dispersion coefficients and Pèclet numbers

\begin{tabular}{|c|c|c|c|c|}
\hline $\begin{array}{c}\text { Volume of impulse of gas } \\
V_{\mathrm{imp}}\left[\mathrm{m}^{3}\right]\end{array}$ & $\begin{array}{c}\text { Volumetric flow rate } \\
\mathrm{F}_{\mathrm{v}}\left[\mathrm{m}^{3} / \mathrm{s}\right]\end{array}$ & $\begin{array}{c}\text { Number of } \\
\text { zone }\end{array}$ & $\begin{array}{c}\text { Axial dispersion coefficient } \\
\qquad D_{L}\left[\mathrm{~m}^{2} / \mathrm{s}\right]\end{array}$ & $\begin{array}{c}\text { Pèclet number } \\
\mathrm{Pe}\end{array}$ \\
\hline \multirow{12}{*}{$5.0000 \cdot 10^{-7}$} & \multirow{4}{*}{$3.3333 \cdot 10^{-7}$} & 1 & $1.2322 \cdot 10^{-3}$ & 2.7 \\
\hline & & 2 & $7.8000 \cdot 10^{-5}$ & 16.5 \\
\hline & & 3 & $1.2322 \cdot 10^{-3}$ & 32.1 \\
\hline & & 4 & $1.2322 \cdot 10^{-3}$ & 75.2 \\
\hline & \multirow{4}{*}{$5.0000 \cdot 10^{-7}$} & 1 & $2.6800 \cdot 10^{-3}$ & 18.9 \\
\hline & & 2 & $7.9000 \cdot 10^{-5}$ & 24.4 \\
\hline & & 3 & $2.6800 \cdot 10^{-3}$ & 22.2 \\
\hline & & 4 & $2.6800 \cdot 10^{-3}$ & 51.9 \\
\hline & \multirow{4}{*}{$6.6667 \cdot 10^{-7}$} & 1 & $4.9390 \cdot 10^{-3}$ & 13.6 \\
\hline & & 2 & $8.0000 \cdot 10^{-5}$ & 32.1 \\
\hline & & 3 & $4.9390 \cdot 10^{-3}$ & 16.0 \\
\hline & & 4 & $4.9390 \cdot 10^{-3}$ & 37.5 \\
\hline
\end{tabular}

2. The solution of the presented model fits experimental results very well.

3. The gas flow is neither plug flow nor perfect mixing under operation condition.

4. The Computer Algebra System - Maple ${ }^{\circledR}$ allows the user to transform model equations to the Laplace domain, solve resulted set of equations and execute inverse Laplace transform just and without errors.

5. CAS - type programs are very helpful for researchers with unusual research or model.

\section{REFERENCES}

1. Cheng A.H-D, Sidauruk P. Approximate inversion of the Laplace transform, The Mathematical Journal, 4, 1994, 76-82.

2. Chen C-S. Analytical and approximate solutions to radial dispersion from an injection well to a geological unit with simultaneous diffusion into adjacent strata, Water Resources Research, 21(8), 1985, 1069-1076.

3. Chen J-S., Liu C-W., Chen C-S., Yen H-D. A Laplace transform solution for tracer tests in a radially convergent flow field with upstream dispersion, Journal of Hydrology, 1996, 183(3-4), 263-275.

4. Chiang L-W. The application of numerical Laplace inversion methods to groundwater flow and solute transport problems, New Mexico Institute of Mining and Technology, 1989.

5. Egonmwan A. O. The Numerical Inversion of the Laplace Transform: Gaver-Stehfest, Piessens, and Regularized Collocation methods, LAP LAMBERT Academic Publishing, 2012.

6. Hassanzadeh H., Pooladi-Darvish M. Comparison of different numerical Laplace inversion methods for engineering applications, Applied Mathematics and Computation, 189, 2007, 1966-1981.

7. Jaradat H. M., Jaradat M. M. M., AwawdehF., Mustafa Z., Alsayyed O. A new numerical method for heat equation subject to integral specifications, Journal of Nonlinear Science and Applications, 9, 2016, 2117-2125.

8. Kocabas I. Application of iterated Laplace transformation to tracer transients in heterogeneous porous media, Journal of the Franklin Institute, 348, 2011, 1339-1362.

9. Rezaei A., Zhan H., Zare M. Impact of thin aquitards on two-dimensional solute transport in an aquifer, Journal of Contaminant Hydrology, 152, 2013, 117-136.

10. Valkó P., Vajda S. Inversion of noise-free Laplace transforms: towards a standardized set of test problems, Inverse Problems in Engineering, 10(5), 2002, 467-483.

11. Wang Q., Zhan H. On different numerical inverse Laplace methods for solute transport problems, Advances in Water Resources, 75, 2015, 80-92.

12. Wójcik M., Szukiewicz M., Kowalik P. Application of numerical Laplace inversion methods in chemical engineering with Maple ${ }^{\circledR}$. The Journal of Applied Computer Science Methods, 7(1), 2015, 5-15.

13. Zhan H., Wen Z., Gao G. An analytical solution of two-dimensional reactive solute transport in an aquifer-aquitard system, Water Resources Research, 45(10), 2009.

14. Zhan H., Wen Z., Huang G., Sun D. Analytical solution of two-dimensional solute transport in an aquifer-aquitard system, Journal of Contaminant Hydrology, 2009, 107(3-4), 162-174.

15. Zhang J.Some innovative numerical approaches for pricing American options, University of Wollongong Thesis Collection, 2007. 